University of Wollongong

Research Online

Australian Institute for Innovative Materials -

Papers

Australian Institute for Innovative Materials

$1-1-2015$

Synthesis of different CuO nanostructures by a new catalytic template method as anode materials for lithium-ion batteries

Xiaohang Ma

University of Science and Technology of China

Shuang Zeng

University of Science and Technology of China

Bangkun Zou

University of Science and Technology of China

Xin Liang

University of Wollongong, University of Science and Technology of China, x1475@uowmail.edu.au

Jia-Ying Liao

University of Science and Technology of China

See next page for additional authors

Follow this and additional works at: https://ro.uow.edu.au/aiimpapers

Part of the Engineering Commons, and the Physical Sciences and Mathematics Commons

Research Online is the open access institutional repository for the University of Wollongong. For further information contact the UOW Library: research-pubs@uow.edu.au 


\title{
Synthesis of different CuO nanostructures by a new catalytic template method as anode materials for lithium-ion batteries
}

\author{
Abstract \\ $\mathrm{CuO}$ powders composed of different rod-like clusters or dandelion-like nanospheres are prepared by a \\ low-temperature thermal decomposition process of $\mathrm{Cu}(\mathrm{OH}) 2$ precursors, which are obtained via a \\ catalytic template method. A tentative mechanism is proposed to explain the formation and \\ transformation of different $\mathrm{Cu}(\mathrm{OH}) 2$ nanostructures. X-ray diffraction, thermogravimetric analysis, \\ scanning electron microscopy, field-emission scanning electron microscopy, transmission electron \\ microscopy, infrared spectra analysis, Brunauer-Emmett-Teller measurements, and galvanostatic cell \\ cycling are employed to characterize the structures and electrochemical performance of these CuO \\ samples. The results show that these $\mathrm{CuO}$ samples obtained after $500^{\circ} \mathrm{C}$ calcination have a stable \\ cycling performance with a reversible capacity of over $587 \mathrm{~mA} \mathrm{~h} \mathrm{~g}^{-1}$ after 50 cycles. The dandelion-like \\ $\mathrm{CuO}$ electrode shows the best rate performance with a high capacity of $511 \mathrm{~mA} \mathrm{~h} \mathrm{~g}^{-1}$ at $4 \mathrm{C}$.

\section{Keywords} \\ ion, lithium, materials, anode, method, template, batteries, catalytic, synthesis, nanostructures, cuo, \\ different \\ Disciplines \\ Engineering | Physical Sciences and Mathematics

\section{Publication Details} \\ Ma, X., Zeng, S., Zou, B., Liang, X., Liao, J. \& Chen, C. (2015). Synthesis of different CuO nanostructures by \\ a new catalytic template method as anode materials for lithium-ion batteries. RSC Advances: an \\ international journal to further the chemical sciences, 5 (71), 57300-57308.

\section{Authors} \\ Xiaohang Ma, Shuang Zeng, Bangkun Zou, Xin Liang, Jia-Ying Liao, and Chunhua Chen
}




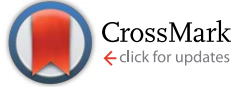

Cite this: RSC Adv., 2015, 5, 57300

Received 7th June 2015

Accepted 23rd June 2015

DOI: $10.1039 / \mathrm{c} 5 \mathrm{ra10825j}$

www.rsc.org/advances

\section{Synthesis of different $\mathrm{CuO}$ nanostructures by a new catalytic template method as anode materials for lithium-ion batteries $\uparrow$}

\begin{abstract}
Xiao-Hang Ma, ${ }^{a}$ Shuang-Shuang Zeng, ${ }^{\mathrm{a}}$ Bang-Kun Zou, ${ }^{a}$ Xin Liang, ${ }^{\text {ab }}$ Jia-Ying Liao ${ }^{a}$ and Chun-Hua Chen*a

CuO powders composed of different rod-like clusters or dandelion-like nanospheres are prepared by a low-temperature thermal decomposition process of $\mathrm{Cu}(\mathrm{OH})_{2}$ precursors, which are obtained via a catalytic template method. A tentative mechanism is proposed to explain the formation and transformation of different $\mathrm{Cu}(\mathrm{OH})_{2}$ nanostructures. X-ray diffraction, thermogravimetric analysis, scanning electron microscopy, field-emission scanning electron microscopy, transmission electron microscopy, infrared spectra analysis, Brunauer-Emmett-Teller measurements, and galvanostatic cell cycling are employed to characterize the structures and electrochemical performance of these $\mathrm{CuO}$ samples. The results show that these $\mathrm{CuO}$ samples obtained after $500{ }^{\circ} \mathrm{C}$ calcination have a stable cycling performance with a reversible capacity of over $587 \mathrm{~mA} \mathrm{~h} \mathrm{~g}^{-1}$ after 50 cycles. The dandelion-like $\mathrm{CuO}$ electrode shows the best rate performance with a high capacity of $511 \mathrm{~mA} \mathrm{~h} \mathrm{~g}^{-1}$ at $4 \mathrm{C}$.
\end{abstract}

\section{Introduction}

The development of advanced portable electronics, electric vehicles and large-scale energy storage systems necessitates the demand for rechargeable lithium-ion batteries with higher energy density than ever before. Therefore, anode materials with higher specific capacity are desired for this purpose. ${ }^{\mathbf{1 , 2}}$ Compared with a graphite anode with a capacity of $370 \mathrm{~mA} \mathrm{~h} \mathrm{~g}^{-1}$, cupric oxide (CuO) has a much higher theoretical capacity of $670 \mathrm{~mA} \mathrm{~h} \mathrm{~g}{ }^{-1}$. Owing also to its advantages of low band-gap energy, nontoxic nature and affordable price, CuO has been investigated as a potential high energy anode material. ${ }^{3-8}$ However, $\mathrm{CuO}$ electrodes suffer from some drawbacks including poor electronic conductivity, low initial columbic efficiency and large volume variation during discharge/charge processes, leading to material pulverization, poor cycling stability and rate capability. Various efforts have been made to solve these problems, including carbon-coating, reducing the particle size into nanometer scales and design of favorable particle morphologies. Recently, well-defined $\mathrm{CuO}$ microstructures with different dimensionalities such as nanoparticles, ${ }^{9}$

${ }^{a}$ CAS Key Laboratory of Materials for Energy Conversions, Department of Materials Science and Engineering, Collaborative Innovation Center of Suzhou Nano Science and Technology, University of Science and Technology of China, Hefei 230026, Anhui, China. E-mail: cchchen@ustc.edu.cn; Fax: +86-551-63601592; Tel: +86-55163606971

${ }^{b}$ Institute for Superconducting and Electronic Materials, University of Wollongong, NSW 2519, Australia

† Electronic supplementary information (ESI) available. See DOI: $10.1039 / \mathrm{c} 5 \mathrm{ra} 10825 \mathrm{j}$ nanoribbons, ${ }^{\mathbf{1 0}}$ nanowires, ${ }^{\mathbf{1 1}}$ nanorods, ${ }^{\mathbf{1 2}}$ nanoleaves, ${ }^{\mathbf{1 3}, \mathbf{1 4}}$ sisallike film, ${ }^{15}$ urchin-nanostructure, ${ }^{16}$ and dandelion-like microspheres, ${ }^{17,18}$ have been synthesized by different methods. Nevertheless, most of these methods require relatively high temperature, time-consuming, and rather complicated procedures. Therefore, in this paper, we develop a simple wetchemical process for the synthesis of different $\mathrm{Cu}(\mathrm{OH})_{2}$ nanostructures at a low temperature without any surfactants and their subsequent transformation into $\mathrm{CuO}$ particles upon further heat treatment. By tailoring the reaction conditions, we can obtain $\mathrm{CuO}$ powders with different nano/micro-structures. As anode materials for lithium-ion batteries, these $\mathrm{CuO}$ electrodes exhibit good cycle performance and excellent rate capability.

\section{Experimental}

Different CuO nanostructures were synthesized by a simple wetchemical process, in which the color of the reaction systems changes at different stages of this synthesis (Fig. 1). First, cupric acetate $\left(\mathrm{Cu}(\mathrm{AC})_{2}\right)$ was dissolved into ethylene glycol (EG) at $70{ }^{\circ} \mathrm{C}$ to obtain a light blue $0.1 \mathrm{M}$ solution (Fig. 1a), and sodium hydroxide $(\mathrm{NaOH})$ was dissolved in deionized water to obtain another solution $(0.2 \mathrm{M})$. Then, different volumes of the $\mathrm{Cu}(\mathrm{AC})_{2}$ solution were added drop-wise in the $\mathrm{NaOH}$ solution $(100 \mathrm{ml})$ under constant magnetic stirring at room temperature. As soon as the $\mathrm{Cu}(\mathrm{AC})_{2}$ solution was mixed with the $\mathrm{NaOH}$ solution, its color became bright blue (Fig. 1b). The volume of the $\mathrm{Cu}(\mathrm{AC})_{2}$ solution added was 20,30 , and $40 \mathrm{ml}$, respectively, to obtain three different solutions. Afterwards, each blue solution was aged at 
room temperature for about $72 \mathrm{~h}$ without stirring to generate a light blue precipitate (Fig. 1c). The light blue precipitates were filtered and washed with distilled water for several times, and then dried at $70^{\circ} \mathrm{C}$ in a vacuum oven for $12 \mathrm{~h}$ to obtain three dark brown powders (Fig. 1d). Subsequently, these powders were calcined at $500{ }^{\circ} \mathrm{C}$ for $6 \mathrm{~h}$ in air and cooled to room temperature. Finally, three black-colored powders were obtained.

The crystalline structures of the light-blue precipitates, darkbrown and black powders were characterized by X-ray diffraction (XRD) using a diffractometer (Rigaku TTR-III, $\mathrm{Cu} \mathrm{K} \alpha$ radiation) in the $2 \theta$ range from $10^{\circ}$ to $70^{\circ}$. The thermogravimetric analysis (TGA) of the dark-brown powders was conducted on a thermal analyzer (Q5000IR, TA Instruments) in air from 30 to $750{ }^{\circ} \mathrm{C}$ at a heating rate of $5{ }^{\circ} \mathrm{C} \mathrm{min}^{-1}$. The morphologies and sizes of the dark-brown and black powders were observed by a scanning electron microscope (JSM-6390LA, JEOL) and a transmission electron microscope (H-800 Hitachi). Also, their specific surface areas were measured by Brunauer-EmmettTeller (BET) method using nitrogen adsorption-desorption isotherms on a Surface Area Analyzer (SA3100, Beckan Coulter). The IR spectrums of the samples were studied by Fourier transform infrared spectrometers (MAGNA-IR750, Nicolet Instuments Co.).

It was proved that the electrochemical performance of the samples before the calcination is with a low coulombic efficiency of about $48.9 \%$ (see ESI Fig. S1 $\dagger$ ). Thus, we mainly focused on the electrochemical properties of the $\mathrm{CuO}$ samples after the calcination. The electrochemical properties of the $\mathrm{CuO}$ samples obtained after the $500{ }^{\circ} \mathrm{C}$ calcination were evaluated in CR2032 coin cells with the CuO samples as the working electrodes and lithium metal as the counter electrode. The $\mathrm{CuO}$ electrode laminates on a copper foil were prepared with acetylene black $(\mathrm{AB})$ as a conductive additive and poly(vinylidene difluoride) (PVDF) as a binder ( $\mathrm{CuO}: \mathrm{AB}: \mathrm{PVDF}=6: 2: 2$ in weight). The laminates were punched into round discs with a diameter of $14 \mathrm{~mm}$. The coin-cells were assembled in an argonfilled glove box (MBRAUN LABMASTER 130). The electrolyte was 1.0 M LiPF6 in ethylene carbonate (EC) and diethyl carbonate (DEC) $(\mathrm{EC}: \mathrm{DEC}=1: 1 \mathrm{v} / \mathrm{v})$, and Celgard 2400 porous membrane was used as the separator. The cells were galvanostatically cycled at $25{ }^{\circ} \mathrm{C}$ on a multi-channel battery cycler (NEWWARE BTS-610) in the voltage rang of 0.01-3.0 V. The impedance spectra of the cells were also measured on an electrochemical workstation (CHI 660A) in the frequency range of 0.005-100 kHz. In order to examine the morphologies of the $\mathrm{CuO}$ electrodes after cycle performance tests, these cells were eventually charged to $3.0 \mathrm{~V}$ and disassembled in a glove box. Then the CuO electrodes were analyzed by field-emission scanning electron microscope (FESEM, S-4800, Hitachi) after being washed with pure DEC to remove the electrolyte residue.

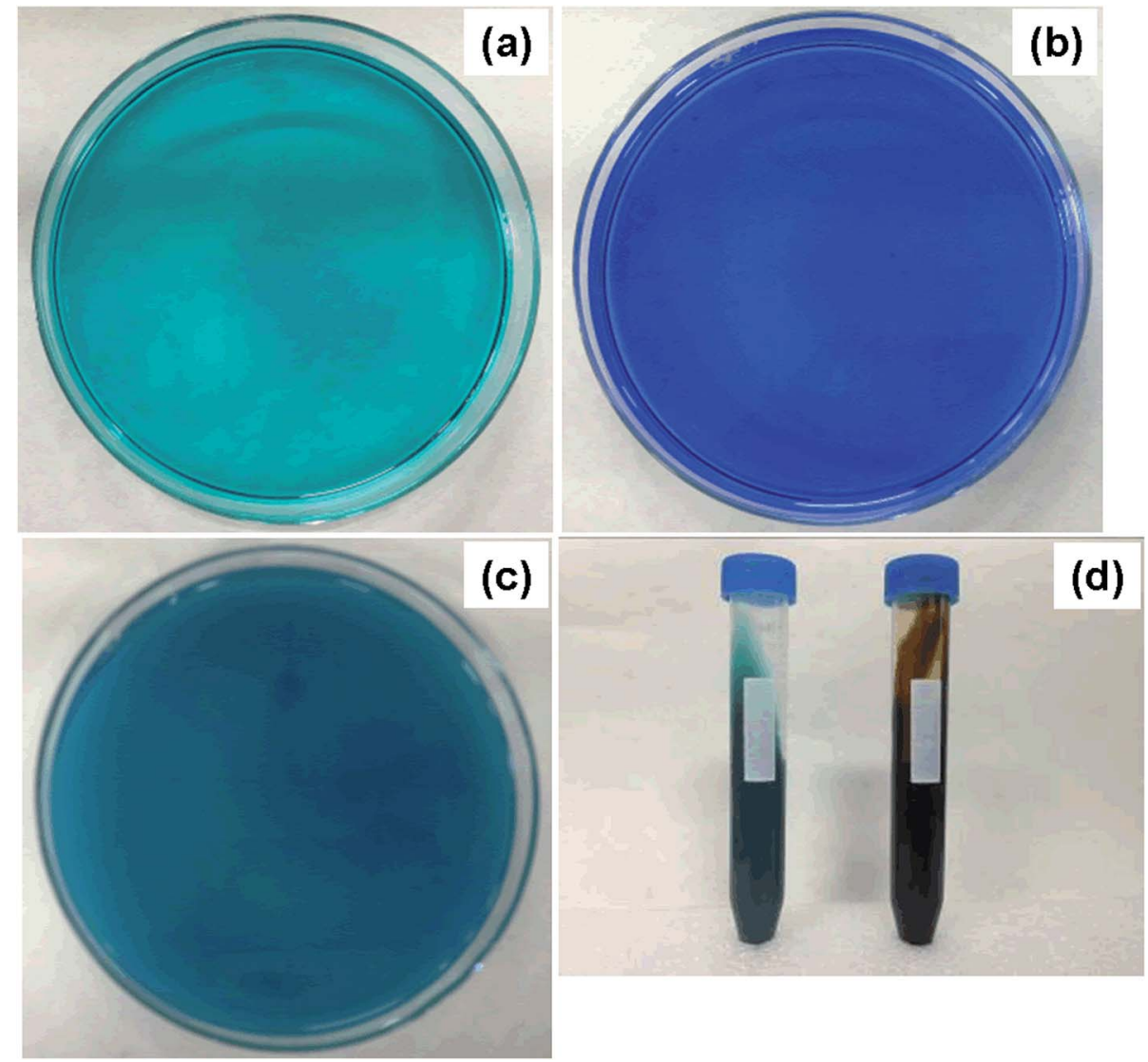

Fig. 1 The color change of the samples in the different stages: (a) $\mathrm{Cu}(\mathrm{AC})_{2}$ dissolved into $\mathrm{EG}$, (b) add $\mathrm{Cu}(\mathrm{AC})_{2}$ solution into $\mathrm{NaOH}$ aqueous solution, (c) aging for $72 \mathrm{~h}$, (d) before and after vacuum drying. 


\section{Results and discussion}

\subsection{Composition and structures of $\mathrm{Cu}(\mathrm{OH})_{2}$ and $\mathrm{CuO}$}

Fig. 2 gives the TGA curves measured under air atmosphere of three dark brown powders prepared by different conditions (Fig. 1d). At around $100{ }^{\circ} \mathrm{C}$, the weight loss of the three dark brown powders is almost the same (about 2.39\%), corresponding to the removal of the absorbed water. After that, there is a huge weight loss process from 100 to $300{ }^{\circ} \mathrm{C}$ for each sample, which may be attributed to the decomposition and removal of the organic ingredients. There is no weight loss above $500{ }^{\circ} \mathrm{C}$ for the three samples, indicating sufficient removal of the organic ingredients and the weight loss is about $6.02 \%, 10.32 \%$ and $14.30 \%$, respectively. It is clear that with increasing the amount of $\mathrm{Cu}(\mathrm{AC})_{2}$ in the reaction systems, the proportions of organic ingredients in the dark brown powders also increases because more EG is brought into the reaction system that can form polymers and be left in the dried products. Also, based on the TGA result, the calcination conditions for the dark brown powders are chosen as $500{ }^{\circ} \mathrm{C}$ for $6 \mathrm{~h}$ in air.

Fig. 3 shows the XRD patterns of the powders obtained at different synthesis stages. The diffraction peaks of the light blue precipitate (Fig. 3a) can be indexed to the orthorhombic $\mathrm{Cu}(\mathrm{OH})_{2}$ (JCPDS no. 80-0656), while the diffraction peaks of the dark brown powder (Fig. 3b) obtained by drying the light blue precipitate at $70{ }^{\circ} \mathrm{C}$ can be indexed to monoclinic CuO (JCPDS card no. 45-0937). This indicates that the $\mathrm{Cu}(\mathrm{OH})_{2}$ powder can be converted into $\mathrm{CuO}$ at a rather low temperatures. ${ }^{19}$ Nevertheless, the peaks in Fig. 3a and b are broad, suggesting that the crystallinity of the as-prepared $\mathrm{Cu}(\mathrm{OH})_{2}$ and $\mathrm{CuO}$ is low. After the $500{ }^{\circ} \mathrm{C}$ calcination, all of diffraction peaks become shaper and can be perfectly indexed to the standard pattern of $\mathrm{CuO}$ crystalline structure (JCPDS card no. 45-0937) (Fig. 3c). Because no other peaks or broad peaks are detected, this powder should be a pure $\mathrm{CuO}$ phase. For the sake of simplicity, the $\mathrm{CuO}$ powders synthesized from different amount of $0.1 \mathrm{M} \mathrm{Cu}(\mathrm{AC})_{2}$

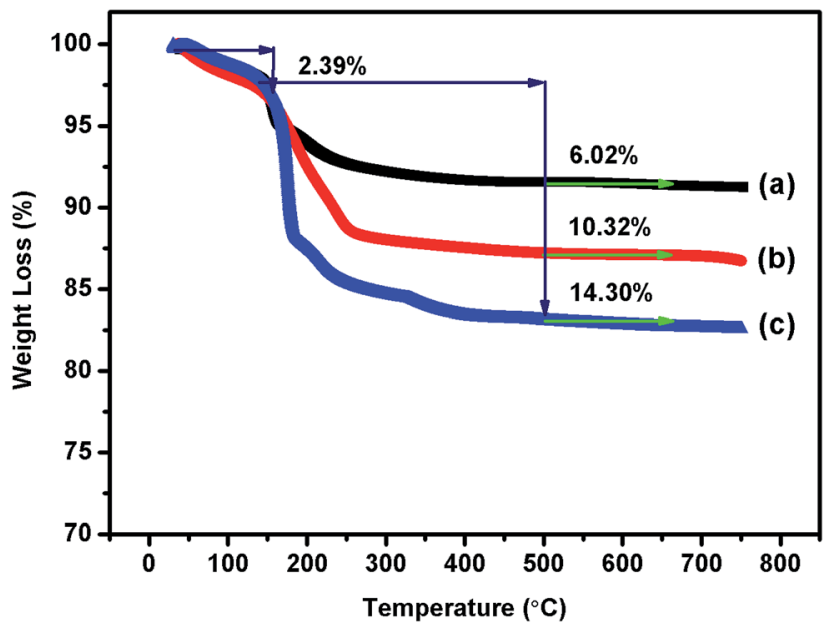

Fig. 2 TGA curves of the dark brown powders made from the different volume of $\mathrm{Cu}(\mathrm{AC})_{2}$ solution: (a) $20 \mathrm{ml}$, (b) $30 \mathrm{ml}$ and (c) $40 \mathrm{ml}$.

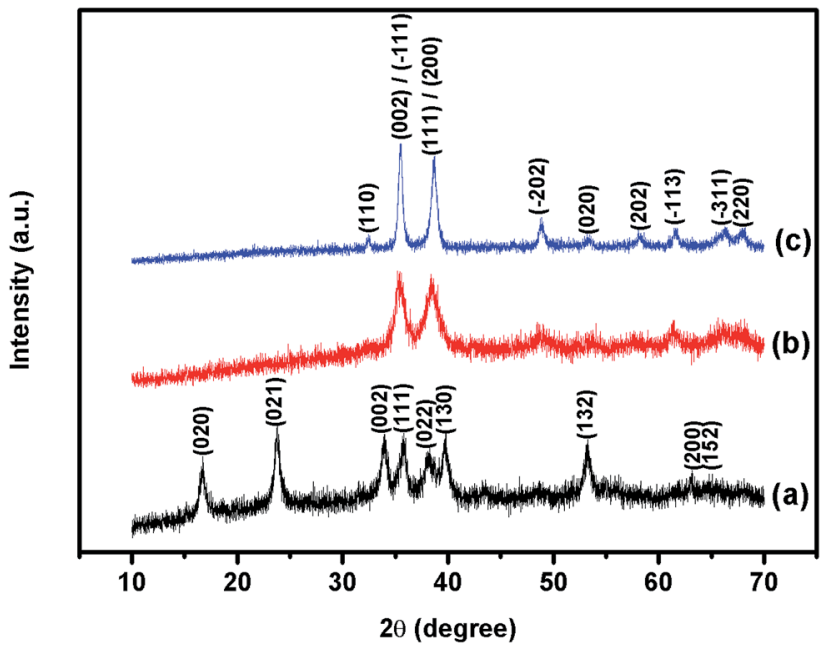

Fig. 3 XRD patterns of as-prepared samples with $40 \mathrm{ml} \mathrm{Cu}(\mathrm{AC})_{2}$ solution as an example: (a) the light blue precipitation, (b) the dark brown powder, (c) the black powders after the $500{ }^{\circ} \mathrm{C}$ calcination.

solution (20, 30, and $40 \mathrm{ml}$ for $100 \mathrm{ml}$ of $0.2 \mathrm{M} \mathrm{NaOH}$ solution) are named as C1, C2 and C3, respectively.

Typical SEM and TEM images of the as-prepared $\mathrm{CuO}$ nanostructures before and after the $500{ }^{\circ} \mathrm{C}$ calcination are shown in Fig. 4. Apparently, the amount of $\mathrm{Cu}(\mathrm{AC})_{2}$ in the reaction system has an important role to determine the nanostructures of the synthesized $\mathrm{CuO}$ samples. When the amount of $\mathrm{Cu}(\mathrm{AC})_{2}$ is little, the synthesized $\mathrm{CuO}$ (C1) is composed of many mono-dispersed nanorods with the diameter of about $20 \mathrm{~nm}$ and the length of from $400 \mathrm{~nm}$ to $800 \mathrm{~nm}$ (Fig. 4a and d). With increasing the amount of $\mathrm{Cu}(\mathrm{AC})_{2}$, the derived $\mathrm{CuO}(\mathrm{C} 2)$ changes its morphology from mono-dispersed nanorods to a mixture of nanorods and nanospheres (Fig. $4 \mathrm{~b}$ and e). A selfassembly process must have occurred in the solution and each nanosphere with a diameter of about $500 \mathrm{~nm}$ is composed of many nanorods. However, with further increasing the amount of $\mathrm{Cu}(\mathrm{AC})_{2}$, only porous $\mathrm{CuO}$ nanospheres with a particle size ranging from 0.5 to $1.0 \mu \mathrm{m}$ are obtained (Fig. $4 \mathrm{c}$ and f). After the $500{ }^{\circ} \mathrm{C}$ calcination, the particle morphologies of these three $\mathrm{CuO}$ powders $(\mathrm{C} 1, \mathrm{C} 2$ and $\mathrm{C} 3)$ may change significantly. The morphology of $\mathrm{C} 1$ turns from mono-dispersed nanorods into irregular particles with particle sizes ranging from 10 to $20 \mathrm{~nm}$ (Fig. $4 \mathrm{~g}$ ). This change may be mainly due to the removal of some organic component that has formed the framework of $\mathrm{C} 1$ before the calcination. Since the inorganic content is low in $\mathrm{C} 1$ before the calcination, the nanorods can be easily broken into small particles during the calcination process. For $\mathrm{C} 2$ and $\mathrm{C} 3$ with more inorganic contents before the calcination, the obtained $\mathrm{CuO}$ powders still maintain the original morphologies after the calcination (Fig. $4 \mathrm{~h}$ and i). More specifically, C3 consists of mono-dispersed spherical particles of about $500 \mathrm{~nm}$ in diameter, which are composed of many nanorods with an average diameter of about $10 \mathrm{~nm}$. The nanorods become thinner from $20 \mathrm{~nm}$ to $10 \mathrm{~nm}$ after the calcination. These nanorods interweave together forming the cluster with an open porous structure after the organic 


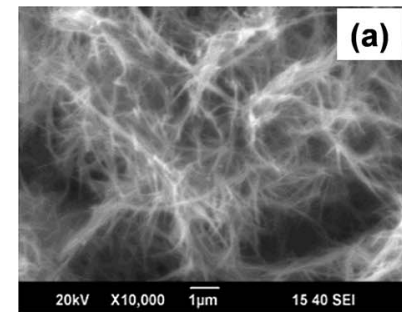

(a)
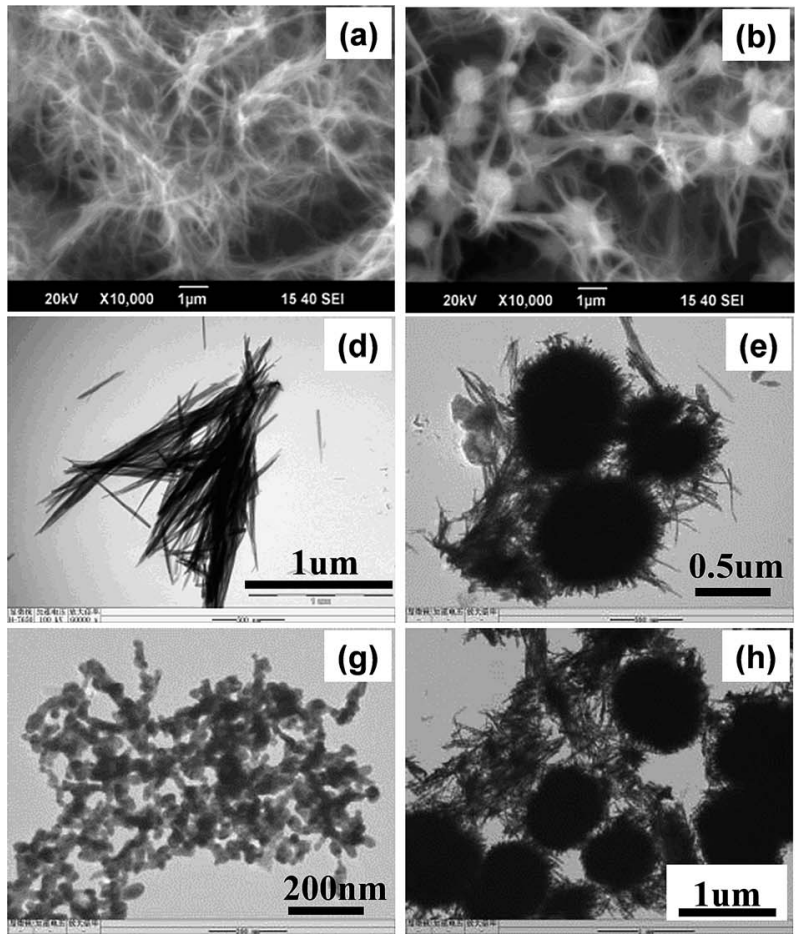
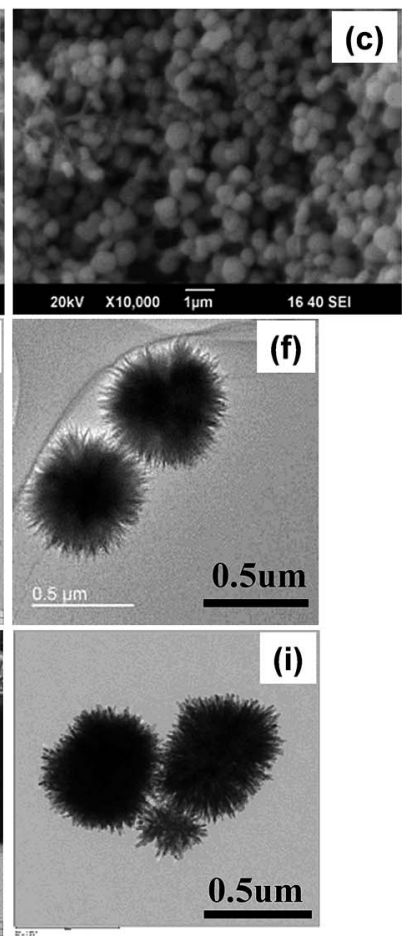

Fig. 4 SEM and TEM images of the prepared CuO powders: ( $a$ and d) $\mathrm{C} 1$; ( $b$ and e) $\mathrm{C} 2$; (c and f) $\mathrm{C} 3$, before the $500^{\circ} \mathrm{C}$ calcination. And TEM images of the corresponding CuO samples: (g) C1; (h) C2; (i) C3, after the $500^{\circ} \mathrm{C}$ calcination.

framework is removed. Such a porous structure is able to facilitate electrolyte penetration into the electrode particles by providing a large contact area between the electrode material and electrolyte, so its electrochemical performance of the prepared materials can be improved.

To further verify the crystallization of the samples with and without high-temperature treatment, the HRTEM images of the C3 before and after the calcination was obtained and the result is shown in Fig. 5. It can be seen that there are only scattered domains with clear fringe lines before the calcination (Fig. 5a) while other areas show no clear fringe lines, indicating the existence of the amorphous $\mathrm{CuO}$ or possible organic components. After the calcination (Fig. 5b), the particles consist of very clear fringe lines with a distance of about $0.25 \mathrm{~nm}$ between the lines, which is consistent with the distance of (002) lattice planes of CuO. This HRTEM result provides a clear evidence of the crystallinity change of $\mathrm{CuO}$ samples before and after the calcination.

\subsection{Reaction mechanism of the catalytic template synthesis approach}

By nitrogen adsorption-desorption measurements, the specific surface areas of the different $\mathrm{CuO}$ samples are shown in Table 1. The specific surface areas of $\mathrm{C} 1, \mathrm{C} 2$ and $\mathrm{C} 3$ before the calcination are $82.01,97.79$ and $116.60 \mathrm{~m}^{2} \mathrm{~g}^{-1}$, respectively. After the

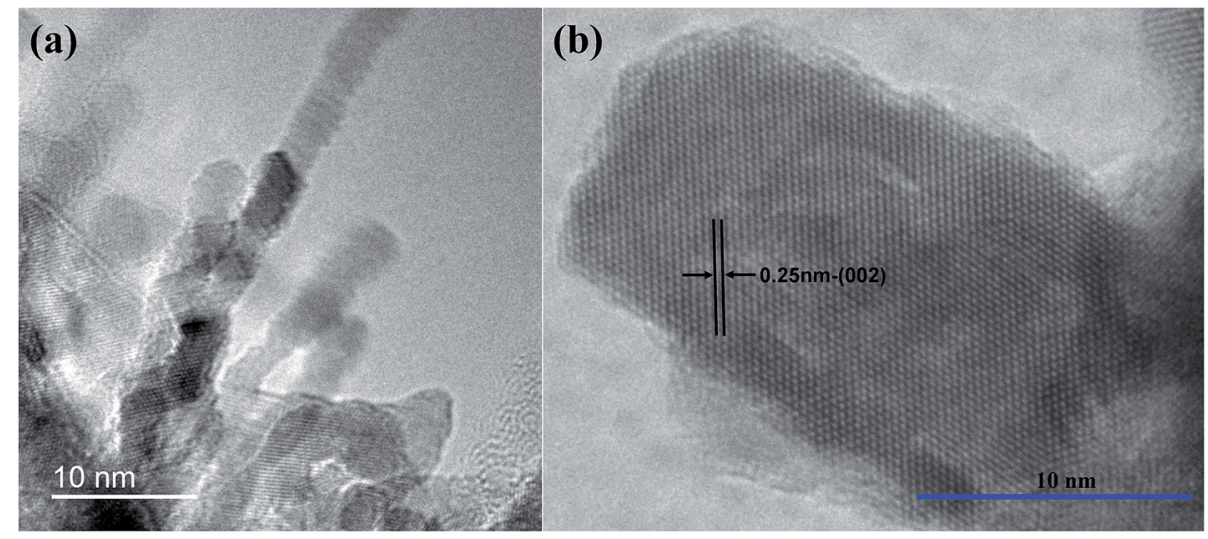

Fig. 5 HRTEM images of the sample C3: (a) before and (b) after the $500{ }^{\circ} \mathrm{C}$ calcination. 
Table 1 The specific surface areas of the different $\mathrm{CuO}$ nanostructures before and after the calcination

\begin{tabular}{|c|c|c|c|c|}
\hline \multirow[b]{2}{*}{ Sample } & \multirow[b]{2}{*}{$V\left(\mathrm{Cu}(\mathrm{AC})_{2}, 0.1 \mathrm{M}\right): V(\mathrm{NaOH}, 0.2 \mathrm{M})$} & \multirow[b]{2}{*}{ Morphology } & \multicolumn{2}{|l|}{$\operatorname{BET}\left(\mathrm{m}^{2} \mathrm{~g}^{-1}\right)$} \\
\hline & & & Before calcination & After calcination \\
\hline $\mathrm{C} 2$ & $3: 10$ & Nanorods-Nanospheres & 97.79 & 15.52 \\
\hline C3 & $4: 10$ & Nanospheres & 116.60 & 29.92 \\
\hline
\end{tabular}

calcination, the specific surface areas decrease substantially, being $9.78,15.52$ and $29.92 \mathrm{~m}^{2} \mathrm{~g}^{-1}$, respectively. The decreases are mainly due to the decomposition of the organic component that leads to the growth of $\mathrm{CuO}$ particles. For $\mathrm{C} 3$, more organic content (evidenced by the TGA analysis in Fig. 2) can suppress the particle growth of $\mathrm{CuO}$ so that its specific surface area is two to three times higher than those of $\mathrm{C} 1$ and $\mathrm{C} 2$.

In order to determine the nature of the organic component in C1, C2 and C3 before the calcination, the IR spectroscopy of C3 before and after the calcination was carried out and the

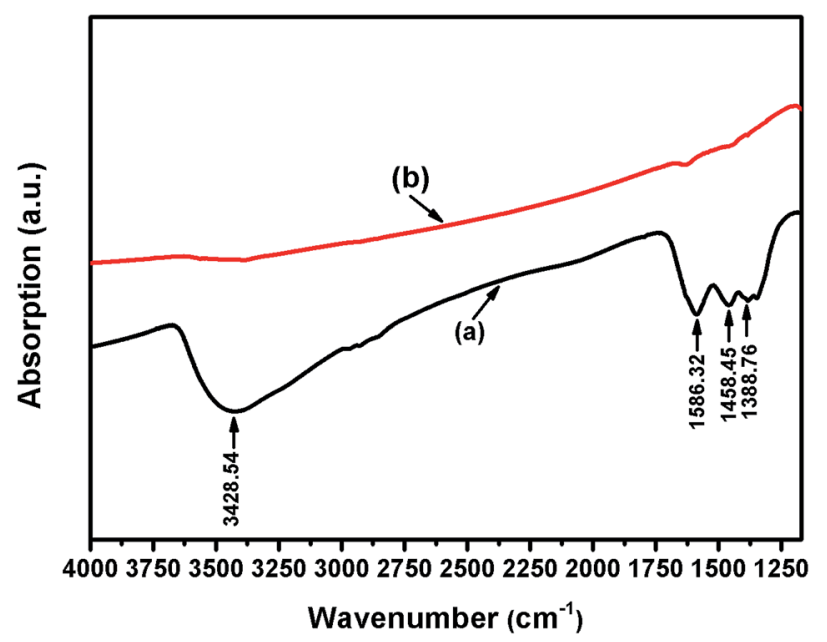

Fig. 6 The IR spectrum of the sample C3: (a) before and (b) after the $500{ }^{\circ} \mathrm{C}$ calcination. results are shown in Fig. 6. On the spectrum of $\mathrm{C} 3$ before the calcination (Fig. 6a), of the broad signal around $3428 \mathrm{~cm}^{-1}$ can be assigned to the vibrational mode of $-\mathrm{OH}$ bond. The signals at about 1586, 1458 and $1388 \mathrm{~cm}^{-1}$ correspond to stretching vibrations of $\mathrm{C}-\mathrm{C}\left(1586 \mathrm{~cm}^{-1}\right)$ and $\mathrm{C}-\mathrm{H}\left(1458\right.$ and $\left.1388 \mathrm{~cm}^{-1}\right)$ bonds, respectively, in a certain kind of polyethylene glycol (PEG). ${ }^{\mathbf{1 3 , 2 0}}$ This result indicates that the monomer molecules EG can be polymerized into PEG molecules under the basic condition $(\mathrm{NaOH})$ and likely with the help of catalytic effect of $\mathrm{Cu}^{2+}$ ions in the $\mathrm{Cu}(\mathrm{AC})_{2}$ solution. After the calcination, all characteristic signals for PEG have disappeared (Fig. 6b), suggesting that the organic component PEG has been removed completely.

On the basis of the above experimental results, a plausible formation mechanism diagram of $\mathrm{CuO}$ nanostructures is proposed as shown in Scheme 1 . When $\mathrm{Cu}(\mathrm{AC})_{2}$ is dissolved into $\mathrm{EG}$, one $\mathrm{Cu}^{2+}$ ion reacts with two EG molecules to form a complex with two positive charges. After the $\mathrm{Cu}(\mathrm{AC})_{2}$ solution is added with a $\mathrm{NaOH}$ solution, the functional groups of the complex are replaced with $\mathrm{OH}^{-}$to form square-planar $\left[\mathrm{Cu}(\mathrm{OH})_{4}\right]^{2-}$ units with a homogeneous deep blue color. ${ }^{21,22}$ Subsequently, in the aging process, two reactions occur simultaneously. One is the polymerization of EG monomers to form poly(ethylene glycol) (PEG) under the conditions of basic environment and the catalytic effect of $\mathrm{Cu}^{2+}$ ions. Another reaction is the transformation of $\left[\mathrm{Cu}(\mathrm{OH})_{4}\right]^{2-}$ into orthorhombic $\mathrm{Cu}(\mathrm{OH})_{2}$ nanocrystallite that is a relatively stable phase..$^{22}$ These $\mathrm{Cu}(\mathrm{OH})_{2}$ nanocrystallites are mainly adsorbed chemically on the PEG molecules by hydrogen bondings to form $\mathrm{Cu}(\mathrm{OH})_{2}-\mathrm{PEG}$ units. Because PEG chain molecules can serve as a template to

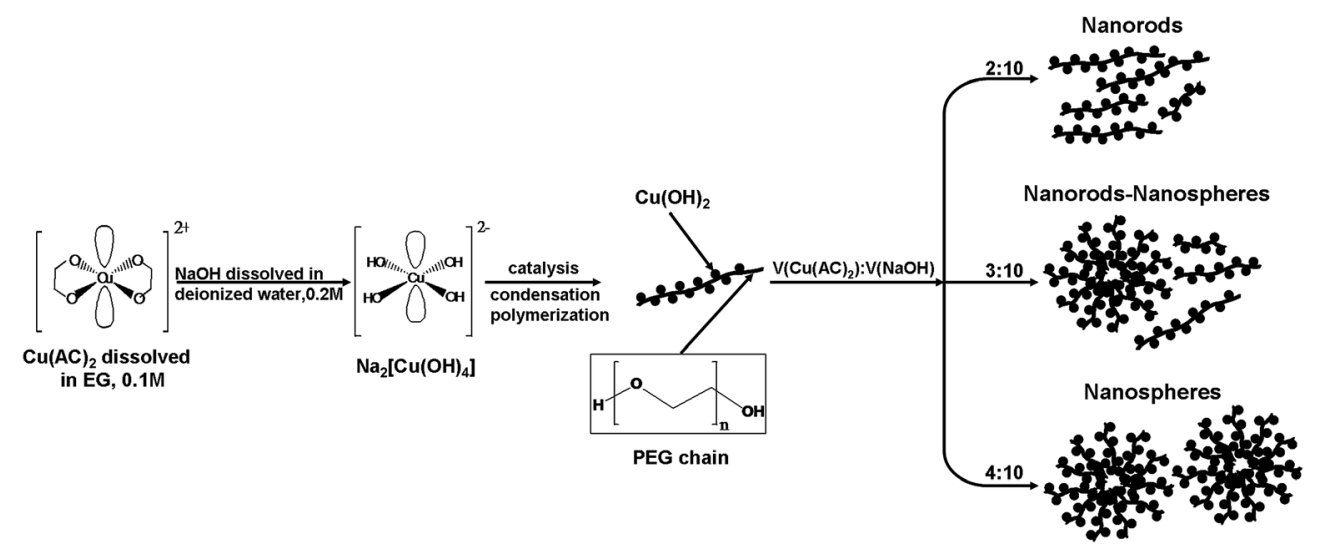

Scheme 1 Schematic illustration of the growth of different $\mathrm{CuO}$ nanostructures under the different volume of $\mathrm{Cu}(\mathrm{AC})_{2}$ solution before the calcination. 

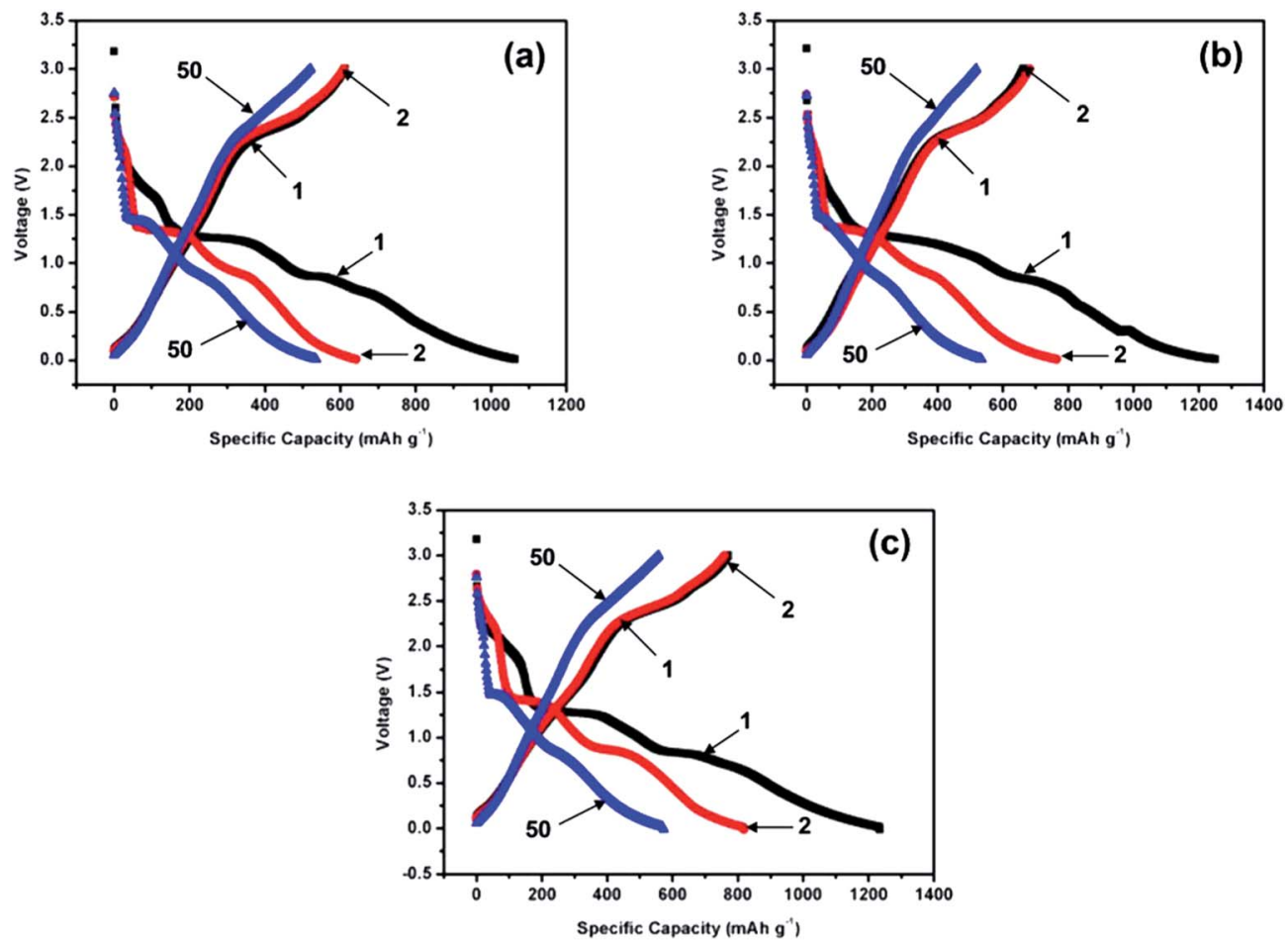

Fig. 7 The discharge and charge profiles of $\mathrm{CuO} / \mathrm{Li}$ half cells: (a) $\mathrm{C} 1$, (b) $\mathrm{C} 2$, and (c) $\mathrm{C} 3$ in the voltage range $0.01-3.0 \mathrm{~V}$ at a current density of $0.2 \mathrm{C}$ $\left(1 \mathrm{C}=670 \mathrm{~mA} \mathrm{~g}^{-1}\right)$. The cycle numbers are indicated in the graphs.

guide the growth of $\mathrm{Cu}(\mathrm{OH})_{2}$ nanocrystallites to form $\mathrm{Cu}(\mathrm{OH})_{2}$ nanorods. It is found here that the amount of the $\mathrm{Cu}(\mathrm{AC})_{2}$ solution also plays an important role in the formation of $\mathrm{Cu}(\mathrm{OH})_{2}$ nanostructures. Clearly, with increasing the amount of $\mathrm{Cu}^{2+}$ ions and EG molecules, $\mathrm{Cu}(\mathrm{OH})_{2}$ nanorods-nanospheres composite structure starts to be formed instead of monodispersed $\mathrm{Cu}(\mathrm{OH})_{2}$ nanorods. Eventually, the nanorods are self-assembled into roughly mono-dispersed nanospheres.

\subsection{Electrochemical properties of $\mathrm{CuO}$ samples}

The as-prepared $\mathrm{CuO}$ samples are used as anode materials for lithium-ion batteries and the voltage profiles of different cycles are shown in Fig. 7. All three electrodes exhibit similar voltage profiles. Taking $\mathrm{C} 3$ as an example, in the first discharge process, there is a voltage drop from $2.25 \mathrm{~V}$ to $1.75 \mathrm{~V}$, which can be attributed to the reduction reaction from $\mathrm{CuO}$ to the intermediate composite copper oxide phase $\mathrm{Cu}_{1-x}{ }^{\mathrm{II}} \mathrm{Cu}_{x}{ }^{\mathrm{I}} \mathrm{O}_{1-x / 2}$. Then, an obvious voltage plateau at about $1.3 \mathrm{~V}$ appears, which corresponds to the $\mathrm{Cu}_{1-x}{ }^{\mathrm{II}} \mathrm{Cu}_{x} \mathrm{O}_{1-x / 2}$ to $\mathrm{Cu}_{2} \mathrm{O}$. And another obvious voltage plateau at about $0.8 \mathrm{~V}$ appears, which corresponds to the conversion reaction that $\mathrm{Cu}$ is driven out from the lattice to form nano-Cu clusters in a $\mathrm{Li}_{2} \mathrm{O}$ matrix, i.e. $\mathrm{Cu}_{2} \mathrm{O}+2 \mathrm{Li} \rightarrow 2 \mathrm{Cu}+$ $\mathrm{Li}_{2} \mathrm{O}^{18,23-26}$ The sloping part below $0.8 \mathrm{~V}$ can be attributed to the formations of a gel-like film and the solid electrolyte interphase films on the surface of the CuO particles. During the subsequent charge step, only two inclined plateau near $1.6 \mathrm{~V}$ and $2.5 \mathrm{~V}$ can be observed, corresponding to the process of nano- $\mathrm{Cu}$ to $\mathrm{Cu}_{2} \mathrm{O}$ and the partial oxidation of $\mathrm{Cu}_{2} \mathrm{O}$ to $\mathrm{CuO}$, respectively. The initial discharge capacities of the three samples are 1072,
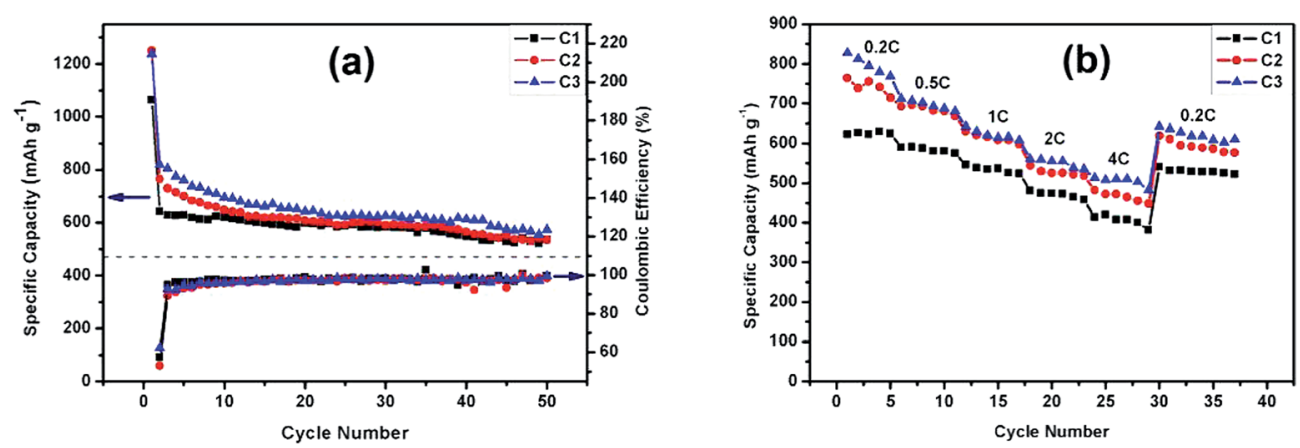

Fig. 8 Electrochemical properties of $\mathrm{CuO}$ samples: (a) cycle performance of the electrodes at a current rate of $0.2 \mathrm{C}$; (b) rate performance of the electrodes at different current density. 
1258 and $1240 \mathrm{~mA} \mathrm{~h} \mathrm{~g}{ }^{-1}$, respectively, which are greater than the theoretical capacity $\left(670 \mathrm{~mA} \mathrm{~h} \mathrm{~g}^{-1}\right)$. The excessive capacities are contributed mainly by the formation of a polymeric gel-like film but a small portion of it is also contributed by the conducting additive acetylene black (AB) and possibly interfacial lithium storage. ${ }^{27}$ The initial coulombic efficiency of these electrodes is $57.2 \%, 52.4 \%, 62.8 \%$ and the initial capacity loss is $39.6 \%, 38.7 \%$, and $33.4 \%$, respectively. These differences in initial discharge capacity, coulombic efficiency and capacity loss are mainly due to the differences in specific surface area

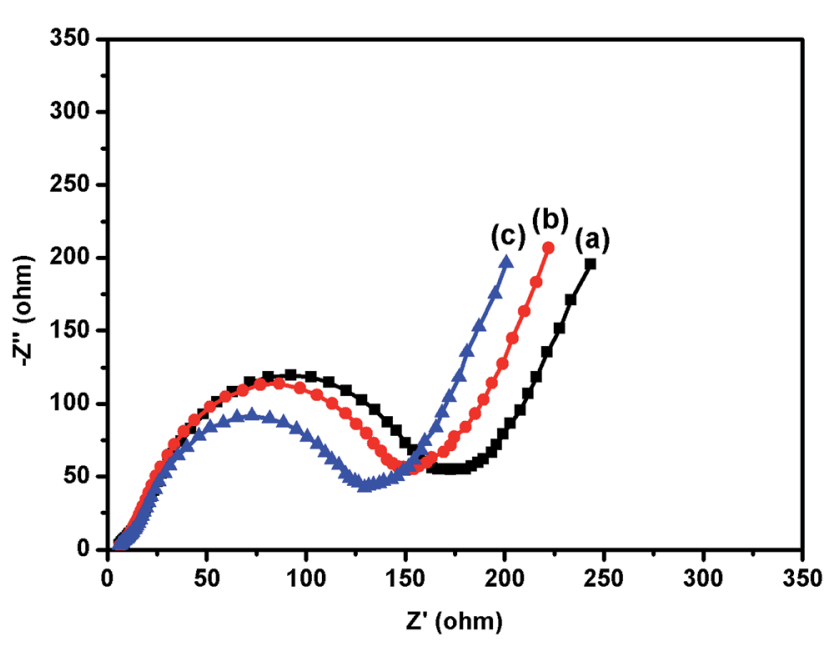

Fig. 9 Impedance spectra of $\mathrm{CuO} / \mathrm{Li}$ cells at the end of charge after 50 cycles at a current density of $0.2 \mathrm{C}$ : (a) C1, (b) C2 and (c) C3. and the microstructure of the three $\mathrm{CuO}$ samples. After 50 cycles, the discharge capacity of three samples is 537, 542 and $587 \mathrm{~mA} \mathrm{~h} \mathrm{~g}^{-1}$, respectively.

The cyclic voltammograms of the three $\mathrm{CuO}$ electrodes (Fig. S2 $\dagger$ ) also show similar results with the cathodic and anodic peaks appearing at corresponding voltages. Also, the calculated initial capacity loss derived from the $\mathrm{CV}$ measurements of these electrodes is $42.9 \%, 42.3 \%$, and $36.4 \%$, respectively, which are consistent with the above trend measured from galvanostatic cycling (39.6\%, 38.7\%, and $33.4 \%$, respectively).

The cycling performance and rate capability of the $\mathrm{CuO}$ electrodes are shown in Fig. 8. All of the electrodes show stable cycling performance and maintain high coulombic efficiency with an average value of about $97.5 \%$ after the first cycle (Fig. 8a). The stable cycling performance of these samples comes from their unique microstructures. Among these three samples, C3 exhibits the best cycling performance that a specific capacity of $587 \mathrm{~mA} \mathrm{~h} \mathrm{~g}^{-1}$ can be obtained after 50 cycles. This result should be attributed to its unique hierarchical architecture that possesses the most open structure and the largest specific surface area among the three samples. Its large specific surface area can help a quick infiltration of electrolyte and shorten the diffusion lengths for both lithium ions and electrons. Thus, compared with $\mathrm{C} 1$ with irregular nanoparticles, C3 with porous mono-dispersed nanospheres can not only offer more sites for $\mathrm{Li}^{+}$accommodation, but also help to accommodate the volume change during the charge/discharge process. Fig. $8 \mathrm{~b}$ shows the rate performance of the $\mathrm{CuO}$ electrodes at various current densities from $0.2 \mathrm{C}$ to $4 \mathrm{C}$. It can be easily seen that C3 also displays the best rate performance with a high

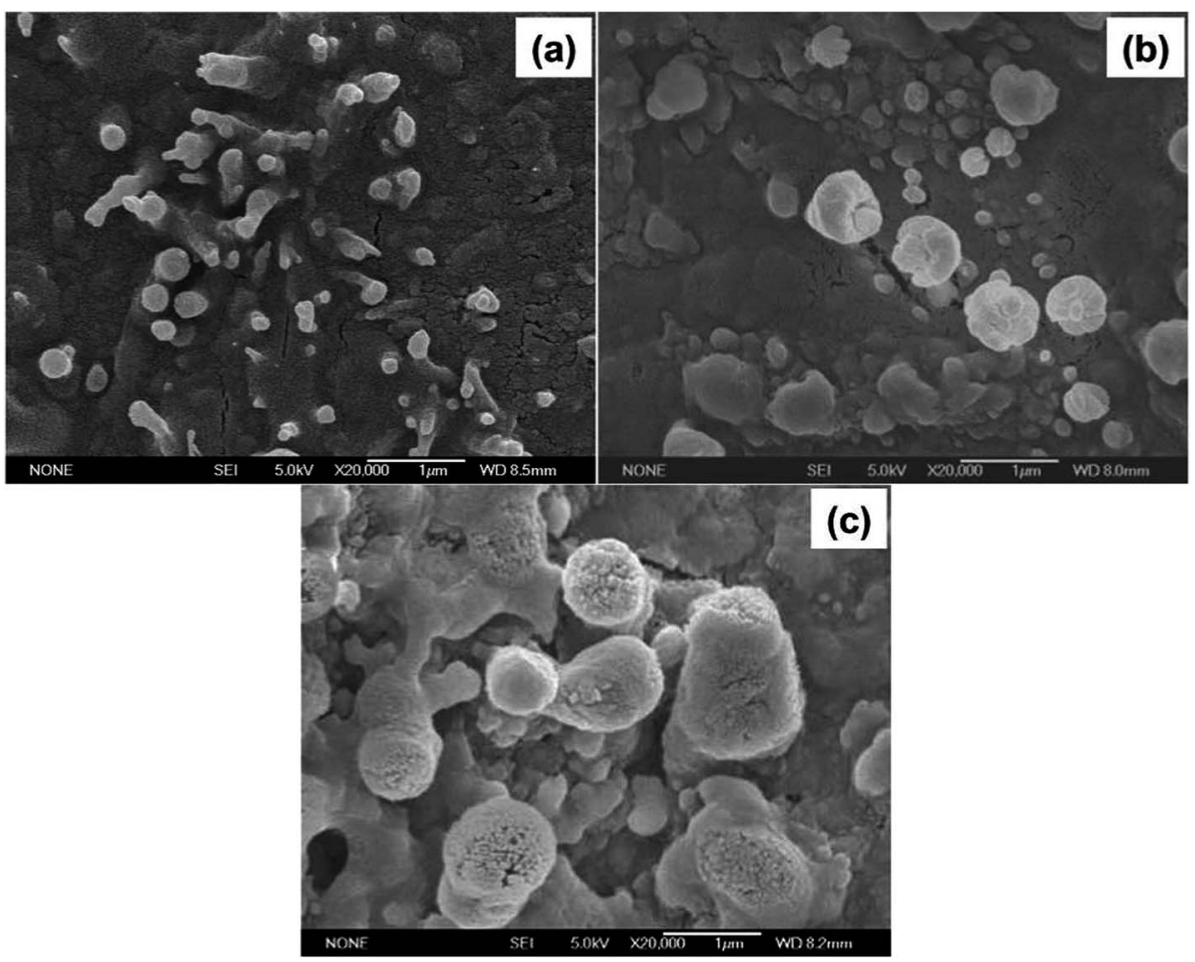

Fig. 10 SEM images of the fully charged CuO electrodes after 50 cycles at a current density of 0.2C: (a) C1, (b) C2 and (c) C3. 
capacity of $796,695,620,553$, and $511 \mathrm{~mA} \mathrm{~h} \mathrm{~g}^{-1}$ at $0.2 \mathrm{C}, 0.5 \mathrm{C}$, $1 \mathrm{C}, 2 \mathrm{C}$, and $4 \mathrm{C}$, respectively. When the charge rate returns to $0.2 \mathrm{C}$, it can still deliver a high reversible capacity of 623 $\mathrm{mA} \mathrm{h} \mathrm{g}^{-1}$. For $\mathrm{C} 2$, its rate performance at a low rate $0.5 \mathrm{C}$ and $1 \mathrm{C}$ ) is similar to $\mathrm{C} 3$, but the discharge capacity is 524 and 463 $\mathrm{mA} \mathrm{h} \mathrm{g}^{-1}$ at $2 \mathrm{C}$ and $4 \mathrm{C}$, respectively, which are lower than those of $\mathrm{C} 3$. For $\mathrm{C} 1$, the discharge capacities are markedly lower than those of C3 and C2. All these results show that C3 displays both outstanding cycling performance and rate capability.

The impedance spectra of the $\mathrm{C} 1, \mathrm{C} 2$ and $\mathrm{C} 3$ electrodes at the end of the charge in the $50^{\text {th }}$ cycle are shown in Fig. 9. The plots are similar to each other in shape, with two overlapped depressed semicircles in the high and intermediate frequency regions and a straight line in the low frequency region. The small semicircle in the high frequency region, which may be contributed from the metallic lithium electrode side, while the semicircle in the intermediate frequency region can be clearly observed, which can be assigned to the charge-transfer impedance at $\mathrm{CuO}$ electrode/electrolyte interface. Obviously, the impedance in $\mathrm{C} 1$ electrode is the largest, followed by $\mathrm{C} 2$ electrode and the smallest is $\mathrm{C} 3$ electrode. Thus, the open microstructure of the electrode is advantageous to reduce the chargetransfer impedance. Therefore, the $\mathrm{C} 3$ electrode shows the most excellent electrochemical performance.

The microstructures of these fully charged $\mathrm{CuO}$ electrodes are investigated after the cycling performance test (Fig. 10). It is found that in Fig. 10a, there are some spherical particles and rod-like particles ranging from $100 \mathrm{~nm}$ to $240 \mathrm{~nm}$ in size distributed in the $\mathrm{C} 1$ electrode film, which are much different from the original nanorods morphology of $\mathrm{CuO}$ in as-calcined C1. This difference is mainly due to the pulverization and agglomeration of the $\mathrm{CuO}$ nanorods caused by the large volume change during electrochemical cycling process. For the C2 electrode (Fig. 10b), in addition to forming the small spherical particles that are similar to $\mathrm{C} 1$ electrode film, there are some large spherical particles of about $0.55 \mu \mathrm{m}$ in size, which still maintain the size of the spherical clusters in original $\mathrm{C} 2$. But the particles here are no longer porous due likely to the filling of the pores by residual electrolyte or related products produced during electrochemical cycling. ${ }^{28}$ For the C3 electrode (Fig. 10c), although the pore size becomes smaller than in the as-calcined C3, it still maintains the open structure composed by a large number of nanorods. Obviously, the more open structure and larger specific surface area of C3 can effectively alleviate the volume and stress changes during the cycling.

\section{Conclusions}

In this paper, we have developed a new and simple catalytic template method and successfully prepared the rod-like or dandelion-like $\mathrm{Cu}(\mathrm{OH})_{2}$ and $\mathrm{CuO}$ particles. The $\mathrm{CuO}$ samples are used as anode materials for lithium-ion batteries and show stable cycling performance with improved rate capability. In particular, the dandelion-like $\mathrm{CuO}$ sample exhibits the best electrochemical performance with high rate capability and reversible cycling performance. This new catalytic template approach also provides a way to prepare other metal oxides with unique nanostructures as the anode materials for high performance lithium-ion batteries.

\section{Acknowledgements}

This study was supported by Hefei Center of Materials Science and Technology (2014FXZY006) and Education Ministry of Anhui Province. We are also grateful to Elementec Ltd in Suzhou.

\section{References}

1 J. M. Tarascon and M. Armand, Nature, 2001, 414, 359-367. 2 M. Armand and J. M. Tarascon, Nature, 2008, 451, 652-657. 3 B. Wang, X. L. Wu, C. Y. Shu, Y. G. Guo and C. R. Wang, J. Mater. Chem., 2010, 20, 10661.

4 A. Li, H. Song, W. Wan, J. Zhou and X. Chen, Electrochim. Acta, 2014, 132, 42-48.

5 L. Feng, Z. Xuan, Y. Bai, H. Zhao, L. Li, Y. Chen, X. Yang, C. Su, J. Guo and X. Chen, J. Alloys Compd., 2014, 600, 162167.

6 X. Liu, N. Bi, C. Feng, S. W. Or, Y. Sun, C. Jin, W. Li and F. Xiao, J. Alloys Compd., 2014, 587, 1-5.

7 W. Zhang, H. Wang, Y. Zhang, Z. Yang, Q. Wang, J. Xia and X. Yang, Electrochim. Acta, 2013, 113, 63-68.

8 Q. Zhang, J. Wang, D. Xu, Z. Wang, X. Li and K. Zhang, J. Mater. Chem. A, 2014, 2, 3865.

9 X. Zhang, D. Zhang, X. Ni, J. Song and H. Zheng, J. Nanopart. Res., 2007, 10, 839-844.

10 F.-S. Ke, L. Huang, G.-Z. Wei, L.-J. Xue, J.-T. Li, B. Zhang, S.-R. Chen, X.-Y. Fan and S.-G. Sun, Electrochim. Acta, 2009, 54, 5825-5829.

11 L. B. Chen, N. Lu, C. M. Xu, H. C. Yu and T. H. Wang, Electrochim. Acta, 2009, 54, 4198-4201.

12 Z. Wang, F. Su, S. Madhavi and X. W. Lou, Nanoscale, 2011, 3, 1618-1623.

13 Z. H. Ibupoto, K. Khun, J. Lu and M. Willander, Appl. Phys. Lett., 2013, 102, 103701.

14 Q. Pan, K. Huang, S. Ni, F. Yang, S. Lin and D. He, J. Alloys Compd., 2009, 484, 322-326.

15 H. Wang, Q. Pan, J. Zhao and W. Chen, J. Alloys Compd., 2009, 476, 408-413.

16 D. Keyson, D. P. Volanti, L. S. Cavalcante, A. Z. Simões, J. A. Varela and E. Longo, Mater. Res. Bull., 2008, 43, 771-775.

17 Z. Zhang, H. Che, Y. Wang, L. Song, Z. Zhong and F. Su, Catal. Sci. Technol., 2012, 2, 1953.

18 S. Q. Wang, J. Y. Zhang and C. H. Chen, Scr. Mater., 2007, 57, 337-340.

19 Y. Cudennec and A. Lecerf, Solid State Sci., 2003, 5, 14711474.

20 C. Dumitriu, C. Pirvu and I. Demetrescu, J. Electrochem. Soc., 2012, 160, G55-G60.

21 G. H. Du and G. van Tendeloo, Chem. Phys. Lett., 2004, 393, 64-69.

22 M. Yang and J. He, J. Colloid Interface Sci., 2011, 355, 15-22.

23 Z. Yin, Y. Ding, Q. Zheng and L. Guan, Electrochem. Commun., 2012, 20, 40-43. 
24 Y. Liu, W. Wang, L. Gu, Y. Wang, Y. Ying, Y. Mao, L. Sun and X. Peng, ACS Appl. Mater. Interfaces, 2013, 5, 9850-9855.

25 S. Ko, J. I. Lee, H. S. Yang, S. Park and U. Jeong, Adv. Mater., 2012, 24, 4451-4456.

26 X.-H. Ma, X.-Y. Feng, C. Song, B.-K. Zou, C.-X. Ding, Y. Yu and C.-H. Chen, Electrochim. Acta, 2013, 93, 131-136.
27 X. Guan, L. Li, G. Li, Z. Fu, J. Zheng and T. Yan, J. Alloys Compd., 2011, 509, 3367-3374.

28 Y. Yu, L. Gu, A. Dhanabalan, C.-H. Chen and C. Wang, Electrochim. Acta, 2009, 54, 7227-7230. 